\title{
Comparative Analysis of Birth Rate and Life Expectancy in Macedonia, Turkey and the European Union
}

\author{
Prof. Dr. Trajko Miceski (Goce Delchev University, Macedonia) \\ Natasha Stojovska (Goce Delchev University, Macedonia)
}

\begin{abstract}
The comparative analysis of birth rate and life expectancy will provide information about the position of Macedonia in relation to Turkey and the EU and also about the factors that have the greatest impact on the population's movement and vitality. This information should help the policy creators in the process of defining and implementing measures for increasing the birth rate and life expectancy of the population, which is aim of every country. In this paper will be put out some theoretical aspects about the economic, social, psychological, technological, cultural and political factors that have impact on the birth rate and life expectancy of the population. Also, the tabular and graphical displays will show the movement of these two demographic features in the period from 1980 to 2011. Changes in birth rate and life expectancy in Macedonia, Turkey and the European Union have been leading to demographic aging of the population in the last three decades. The birth rate in these countries shows a trend of continuous decline, despite the gradual increase in life expectancy of the population. Although the declined birth rate and increased life expectancy of the population have been a common features of these countries in the last decades, the percentage of this changes is different for each country.
\end{abstract}

\section{Introduction}

The statistical data aboutthe movement of global population points out the slower pace of its growth. Indeed, a trend of self-destruction, expressed through reduced birth rate of the world population is becoming more intensive. Inevitable consequences of this trend are reduced number of live births, on one hand and demographic aging of the population, on the other hand.

The problem with falling birth rates indicates several trends that have smaller or bigger contribution to this negative movement of the population. They appear as a consequence of modern living expressed through improved general living conditions, women's higher level of education and participation in the labor market, professional orientation of young population, advanced technology. In fact, the economic, social and cultural development is increasing the need for professional development, personal satisfaction and leisure time, on one hand, but also is reducing the desire for children, on the other hand. Consequently, there is a reduction innumber of live births, reductionin number of marriages and increasein number of divorces.

Increased life expectancy is a result of numerous factors, including clean water, better prenatal care,better nutrition, wider and more accessible healthcare, improved medicines, new drugs and technologies that allow prevention and earlier treatment of health problems. The trend of continuous increasing of life expectancy means that today the population over 50 years is becoming more numerous compared to the past.

\section{Comparative Analysis of Birth Rate in Macedonia, Turkey and the European Union}

The birth rate in Macedonia, Turkey and the EU countries is showing a trend of declining. With other word, there is a reduction in the number of live births per woman as a result of the impact of many factors. The development tendency of this demographic variable for each country i.e. communityofnations, is presented tabular and graphic.

Tabular and graphic displays show a significant decline in the birth rate in these countries in the last three decades. Despite past and current situation, the prediction for the future is also showing a declining movement, if the factors of influencewould not be identified and appropriate measures to overcome such situations would not be taken.

What we can first notice from the figure above is the trend of rapidly declining birth rate in the beginning of the analyzed period(especially in Turkey), than its slower decline in the second decade and stagnation or minimal decline in recent years. Despite this common trend, the percentage of change is different for each country. In Macedonia, the percentage of decline in the birth rate is $49.5 \%$, in Turkey is $50.7 \%$ and in the EU is $25.2 \%$. We can conclude that Turkey still has the highest birth rate of 17.4 live births per 1,000 inhabitants, despite its greatest fall in the analyzed period. On the second place is Macedonia with 10.9 live births per 1,000 inhabitants and the EU with 10.4 live births per 1,000 inhabitants is in the end, though the smallest percentage of change in the analyzed period. 


\begin{tabular}{|c|c|c|c|}
\hline Year & Birth rate in Macedonia & Birth rate in EU & Birth rate in Turkey \\
\hline 1980 & 21,6 & 13,9 & 35,2 \\
\hline 1981 & 21,3 & 13,5 & 34,5 \\
\hline 1982 & 21,0 & 13,4 & 33,6 \\
\hline 1983 & 20,7 & 13,1 & 32,7 \\
\hline 1984 & 20,3 & 13,0 & 31,7 \\
\hline 1985 & 19,9 & 12,8 & 30,7 \\
\hline 1986 & 19,4 & 12,7 & 29,7 \\
\hline 1987 & 19,0 & 12,8 & 28,6 \\
\hline 1988 & 18,6 & 12,7 & 27,7 \\
\hline 1989 & 18,3 & 12,4 & 26,8 \\
\hline 1990 & 17,9 & 12,4 & 26,0 \\
\hline 1991 & 17,4 & 12,0 & 25,4 \\
\hline 1992 & 17,0 & 11,7 & 24,8 \\
\hline 1993 & 16,5 & 11,4 & 24,3 \\
\hline 1994 & 15,9 & 11,1 & 23,9 \\
\hline 1995 & 15,3 & 10,8 & 23,5 \\
\hline 1996 & 14,7 & 10,8 & 23,1 \\
\hline 1997 & 14,1 & 10,7 & 22,7 \\
\hline 1998 & 13,5 & 10,5 & 22,3 \\
\hline 1999 & 13,0 & 10,5 & 21,9 \\
\hline 2000 & 12,6 & 10,6 & 21,5 \\
\hline 2001 & 12,3 & 10,4 & 21,0 \\
\hline 2002 & 12,0 & 10,3 & 20,6 \\
\hline 2003 & 11,8 & 10,3 & 20,2 \\
\hline 2004 & 11,6 & 10,5 & 19,8 \\
\hline 2005 & 11,4 & 10,4 & 19,4 \\
\hline 2006 & 11,3 & 10,6 & 19,0 \\
\hline 2007 & 11,2 & 10,6 & 18,7 \\
\hline 2008 & 11,1 & 10,9 & 18,4 \\
\hline 2009 & 11,0 & 10,7 & 18,1 \\
\hline 2010 & 10,9 & 10,7 & 17,7 \\
\hline 2011 & 10,9 & 10,4 & 17,4 \\
\hline \multicolumn{4}{|c|}{ Prediction } \\
\hline 2014 & 8,2 & 9,4 & 14,2 \\
\hline 2015 & 7,7 & 9,3 & 13,6 \\
\hline 2016 & 7,4 & 9,2 & 13,1 \\
\hline 2017 & 7,0 & 9,1 & 12,5 \\
\hline 2018 & 6,6 & 9,0 & 11,9 \\
\hline
\end{tabular}

Table 1. Movement of birth rate in Macedonia, Turkey and the EU in the period 1980-2011 Source: World Bank, World Development Indicators

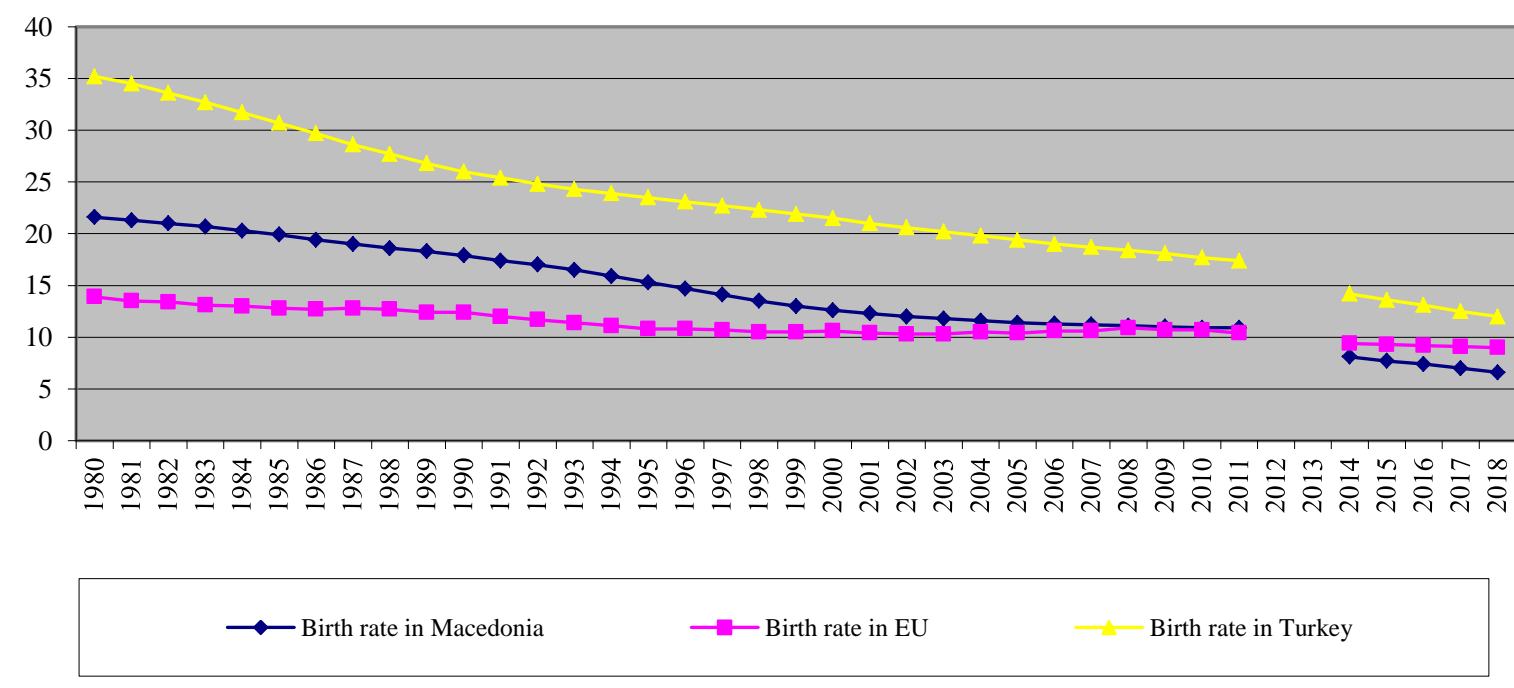

Figure 1: Movement of birth rate in Macedonia, Turkey and the EU in the period 1980-2011 


\subsection{Factors for the Declining Birth Rate}

There are many factors that determine the natural movement of the population. They can be classified in this way:

a) Biological constraints

Besides changes in woman's reproductive period, expressed through lower limits of menstruation obtaining and disappearance, it seems that today more present factor is sterility. Most causes for infertility come from the lifestyle and fast pace of life (stress, infections, cigarettes, alcohol and drug addiction, unhealthy diet, use of chemical substances for muscle mass and others) (Preventus, 2013).

\section{b) Economic conditions}

The consequences of the global economic and financial crisis, expressed through job insecurity and increased costs of living, lead to endangering the life existence of married couples, and thus limiting the number of children. Housing, employment and cash incomes are very important conditions for making a decision of having a child. Not having own house, rent living, livelihood with minimum social income or income from only one family member are common reasons for delaying marriage and having children, although there is a desire for it (Demerdjiev, 1998).

c) Advanced technology

The advance in technology and knowledge in all areas related to birth also contributes to the reduced number of births. Unlike traditional unreliable methods as counting the fertile days, abstinence and others, technical technological development in medicine allows the application of far more reliable methods, such as contraceptive pills, condoms, surgical sterilization and various injections and implants (Hatcher, et. al, 1984).

\section{d) Social factors}

Living environment has great impact on the decision about marriage and child. Life values, experiences and advices of the closer and extended family, the behavior within the family and the relationships between all family members is very likely to affect the reproductive behavior of the potential parents (Ekerman, 1966). In this regard, families today are often composed by husband, wife and one, perhaps two children, and their mutual relations are characterized with frequent conflicts, misunderstandings, divorces.

The state's role is particularly important in terms of financial support and legislation in this area. A common practice in employment policy is advantage to have those women who already have children and also job insecurity if the woman get pregnant. That's why young, but still not married girls postpone the marriage and women who had just got married postpone the childbearing until they get sufficient experience and build a career.

e) Changed human psychology

Today, the need for hedonism is increasingly expressed. Namely, because of the growth of the disposable income, stressful lifestyle and lack of time, young people have increased need for indulgence, small pleasures and better leisure time. In this respect, the man emerges as selfish and egoistic creature whose priority is personal pleasure, not sacrificing and giving pleasure to own child.

\section{f) Reduced number of marriages and increased number of divorces}

Nowadays, there is an increasing number of persons who have never married, people who get marry at older age and single parent families. Many factors are affecting this trend, including:

- Increased participation of women in the labor market

Today, women's level of education, intelligence and productivity is equal to that of the men and this allows same jobs, earnings and absence of sex discrimination in employment, on the one hand, but also reduces the interest for marriage, on the other hand.

\section{- $\quad$ Lower relative income of men}

Today, increased employment of the women compared to the past means more equal incomes of husband and wife. With other words, the relative earnings of the wife are increasing and the relative earnings of the husband are reducing. To feel superior and powerful, men first want to provide a reliable source of income before get marry. While accomplish this, they postpone the marriage. Also, this is often factor for divorce.

\section{- $\quad$ Reduced benefits of family formation}

Unlike earlier, when most important roles for the woman were housewife, mother and wife, today, among all this stands out the role of career woman. This change in priorities indirectly has influence on reduced number of marriages. In choosing partner, woman sets higher criteria in terms of education, intelligence and financial condition i.e. she wants the potential husband to be appropriate to her status (Paserman, 2003). The search for appropriate partner leads to delaying the marriage or not marring.

\section{- $\quad$ Increased number of same sex couples and marriages}

Besides marriage between man and woman, the marriage between persons from the same sex is becoming more frequent in countries where this type of marriage is legally permitted. Although in Macedonia, Turkey and 
most EU countries this is still not allowed, there are many same-sex couples who are living together or have relationship. This trend means reduced number of heterosexual marriages.

- Better access to contraception and abortion

Big impact on the reduced number of live births has the use of contraceptive pills and abortion. These factors are more intensive compared to the past.

\section{Comparative Analysis of Life Expectancy in Macedonia, Turkey and the European Union}

Life expectancy in Macedonia, Turkey and the EU countries is slowly increasing. This means demographic aging of the population in these countries as a result of the impact of several factors. The development tendency of this demographic variable is presented tabular and graphic.

In 1980, Turkey has the shortest life expectancy of 58.7 years, Macedonia with 68.7 years is after and EU with 72.9 years has the longest life expectancy. This difference in length of life expectancy, especially among Turkey, on one hand and Macedonia and the EU, on the other hand, is significantly minimized in 2011, when the length of life expectancy in Macedonia (74,9) and Turkey $(74,5)$ is relatively the same. By contrast, the EU, with 80,2 years life expectancy, is still in a significantly better position. The percentage of change in this analyzed period is $9 \%$ in Macedonia, $27 \%$ in Turkey and $10 \%$ in the EU. This means that Turkey has made the biggest progress in this area, but, together with Macedonia, are still far from the level of the EU countries.

\begin{tabular}{|c|c|c|c|}
\hline Year & $\begin{array}{l}\text { Life expectancy in } \\
\text { Macedonia }\end{array}$ & $\begin{array}{c}\text { Life expectancy in } \\
\text { EU }\end{array}$ & $\begin{array}{c}\text { Life expectancy in } \\
\text { Turkey }\end{array}$ \\
\hline 1980 & 68,7 & 72,9 & 58,7 \\
\hline 1981 & 68,8 & 73,2 & 59,3 \\
\hline 1982 & 68,9 & 73,5 & 59,9 \\
\hline 1983 & 69,2 & 73,5 & 60,6 \\
\hline 1984 & 69,4 & 73,8 & 61,1 \\
\hline 1985 & 69,8 & 73,9 & 61,7 \\
\hline 1986 & 70,1 & 74,1 & 62,3 \\
\hline 1987 & 70,4 & 74,4 & 62,8 \\
\hline 1988 & 70,7 & 74,6 & 63,3 \\
\hline 1989 & 70,9 & 74,7 & 63,8 \\
\hline 1990 & 71,1 & 74,8 & 64,3 \\
\hline 1991 & 71,3 & 74,9 & 64,8 \\
\hline 1992 & 71,5 & 75,3 & 65,3 \\
\hline 1993 & 71,7 & 75,4 & 65,8 \\
\hline 1994 & 71,9 & 75,7 & 66,4 \\
\hline 1995 & 72,1 & 75,8 & 67,0 \\
\hline 1996 & 72,3 & 76,0 & 67,6 \\
\hline 1997 & 72,5 & 76,3 & 68,2 \\
\hline 1998 & 72,8 & 76,5 & 68,8 \\
\hline 1999 & 73,0 & 76,7 & 69,4 \\
\hline 2000 & 73,2 & 77,1 & 70,0 \\
\hline 2001 & 73,5 & 77,4 & 70,6 \\
\hline 2002 & 73,6 & 77,6 & 71,1 \\
\hline 2003 & 73,8 & 77,7 & 71,6 \\
\hline 2004 & 74,0 & 78,2 & 72,0 \\
\hline 2005 & 74,1 & 78,3 & 72,4 \\
\hline 2006 & 74,2 & 78,7 & 72,8 \\
\hline 2007 & 74,3 & 78,9 & 73,2 \\
\hline 2008 & 74,4 & 79,1 & 73,5 \\
\hline 2009 & 74,6 & 79,3 & 73,9 \\
\hline 2010 & 74,7 & 79,6 & 74,2 \\
\hline 2011 & 74,9 & 80,2 & 74,5 \\
\hline
\end{tabular}

Table 2: Movement of life expectancy in Macedonia, Turkey and the EU in the period 1980-2011 Source: World Bank, World Development Indicators 


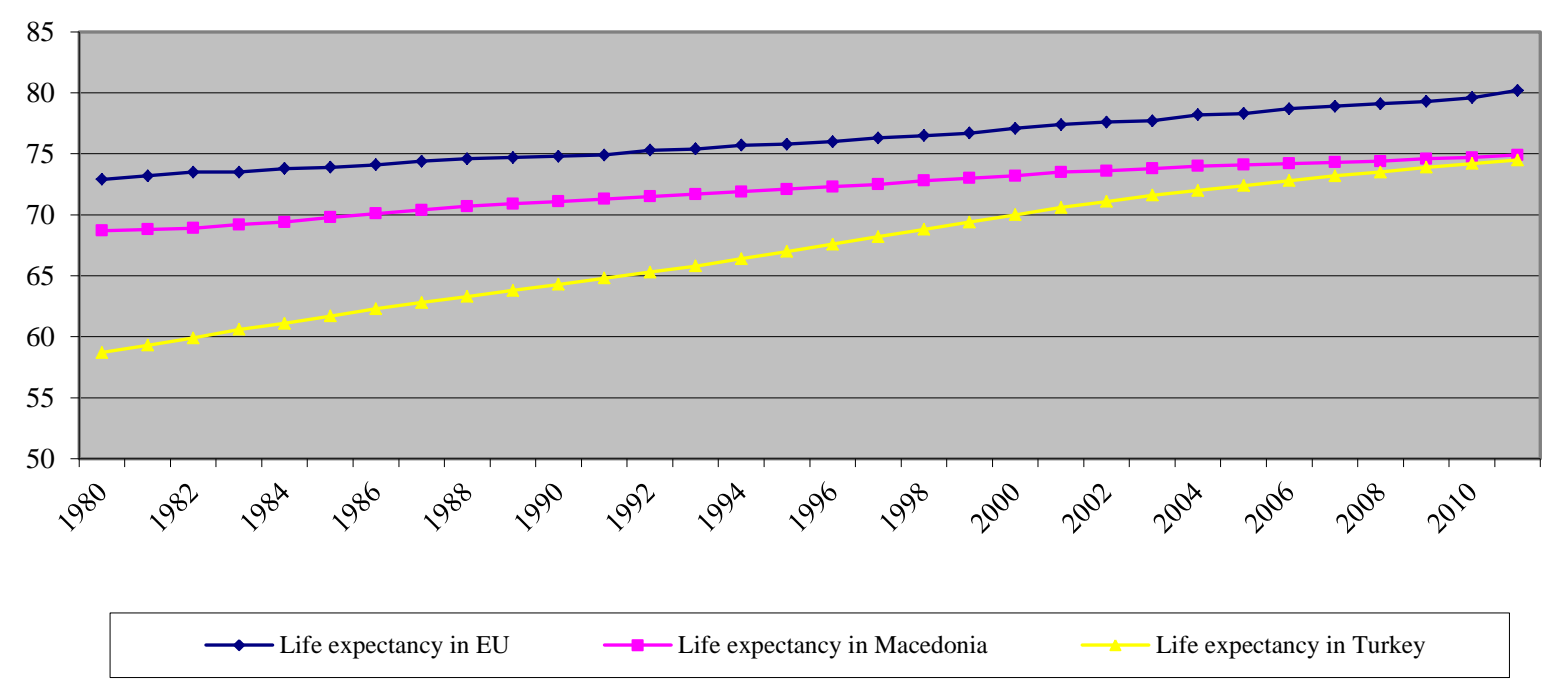

Figure 2: Movement of life expectancy in Macedonia, Turkey and the EU in the period 1980-2011

\subsection{Factors for Increased Life Expectancy}

The trend of constant increase of life expectancy is a result of many changes taking place in 21 st century, such as: clean water for the most people, better public and personal hygiene, vaccination against the most addictive diseases, new medical treatments for various chronic diseases, better nutrition, especially during pregnancy and childhood, decreased mortality rate, more physical activity, rise of the cash-rich and time-poor segment, search for greater value, growth of ethical consumption, emphasis on health and healthy lifestyle, the desire for enjoying small pleasures and many more.

Because of the growing awareness of individuals about their ability and responsibility to influence their health, increasing numbers of evidence about relation between diseases and diet and the transition from state welfare to individual welfare, more attention is paid to the lifestyle management. The recognition that the diet has a significant contribution to health means that people today are more careful in choosing a product.

Today, the old population has significant differences compared to the past. They are healthier, more active, richer, they travel more, want to experiment with food and are open to new technology. This means that they are keeping their young spirit and life style.

\section{Conclusion}

From the conducted analysis, we can conclude that the situation with the birth rate in Macedonia, Turkey and the European Union is worrying. The continuing rate of its decline indicates the need for urgent measures at state level. These measures include greater financial support for young parents, changes in labor law towards better mother's protection, job for every mother, public propaganda about the positive effects of having a child and the negative effects of an abortion.

Despite falling birth rates, the continuing increase in life expectancy suggests further encourage and support of this trend through broader and more accessible health care, better living conditions and promotion of healthy lifestyle.

\section{References}

- Demerdjiev, 1998. Avtogenicid,pechatnica Sofija, Bogdanci.

- Ekerman, 1996. Psihodinamika porodičnog života. Grafički zavod, Titograd.

- Hatcher, Robert A. Guest, Felicia. Stewart, Felicia. Stewart, Gary K. Trussel, James. Frank, Erica, 1984, Contraceptive Technology. $12^{\text {th }}$ revised edition. New York: Irvington, p.56

- Paserman, 2003. "Waiting for Mr.Right: Rising inequality and declining marriage rates". 2003. Journal of urban economics, $\mathbf{5 3}$, no. 2

- Preventus, 2013.http://preventus.mk/index.php?option=com_content\&view=article\&id=2426:2012-08-01$00-21-39 \&$ catid $=61$ : zanegoizanea $\&$ Itemid $=80$

- World Bank, 2014.World Development Indicators, http://databank.worldbank.org/data/views/reports/tableview.aspx 